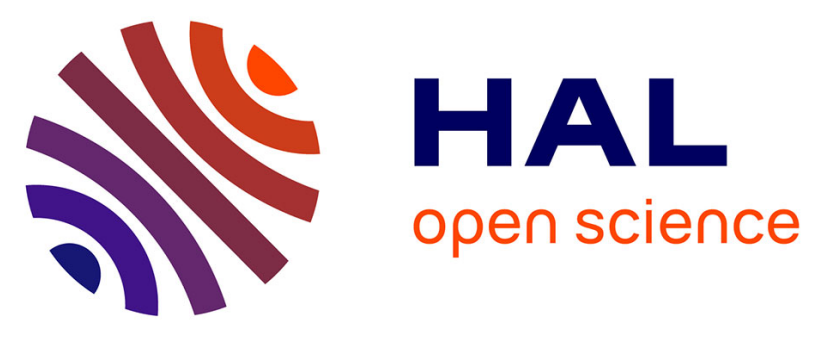

\title{
Detection in and circulation of Bluetongue virus among domestic ruminants in Madagascar
}

Soa Fy Andriamandimby, Cyril Viarouge, Jean-Pierre Ravalohery, Jean Marc

Reynes, Corinne Sailleau, Luciano Michael Tantely, Nohal Elissa, Eric

Cardinale, Amadou Alpha Sall, Stéphan Zientara, et al.

\section{To cite this version:}

Soa Fy Andriamandimby, Cyril Viarouge, Jean-Pierre Ravalohery, Jean Marc Reynes, Corinne Sailleau, et al.. Detection in and circulation of Bluetongue virus among domestic ruminants in Madagascar. Veterinary Microbiology, 2015, 176 (3-4), pp.268-273. 10.1016/j.vetmic.2015.02.009 . hal-01290712

\section{HAL Id: hal-01290712 \\ https://hal.science/hal-01290712}

Submitted on 28 Feb 2018

HAL is a multi-disciplinary open access archive for the deposit and dissemination of scientific research documents, whether they are published or not. The documents may come from teaching and research institutions in France or abroad, or from public or private research centers.
L'archive ouverte pluridisciplinaire $\mathbf{H A L}$, est destinée au dépôt et à la diffusion de documents scientifiques de niveau recherche, publiés ou non, émanant des établissements d'enseignement et de recherche français ou étrangers, des laboratoires publics ou privés. 
1 Title: Detection in and Circulation of Bluetongue Virus among domestic ruminants in

2 Madagascar

3

4 Running Title: Bluetongue Virus in Madagascar

5

6 Authors

7 Soa Fy Andriamandimby ${ }^{1}$, Cyril Viarouge ${ }^{2}$, Jean-Pierre Ravalohery ${ }^{1}$, Jean-Marc Reynes ${ }^{1}$,

8 Corinne Sailleau ${ }^{2}$, Michael Luciano Tantely ${ }^{3}$, Nohal Elissa ${ }^{3}$, Eric Cardinale ${ }^{4}$, Amadou Alpha

9 Sall $^{5}$, Stephan Zientara ${ }^{2}$, Jean-Michel Heraud ${ }^{1}$

10

11 Affiliations

$12{ }^{1}$ Virology Unit, Institut Pasteur de Madagascar, Antananarivo, Madagascar

$13{ }^{2}$ Anses-Laboratoire Santé Animal-UMR 1161, Maisons-Alfort, France

$14{ }^{3}$ Medical Entomology Unit, Institut Pasteur de Madagascar, Antananarivo, Madagascar

$15{ }^{4}$ CIRAD, UMR CMAEE, F-97490 Sainte-Clotilde, La Réunion, France; INRA, UMR 1309

16 CMAEE, Montpellier, France

$17{ }^{5}$ Virology Unit, Institut Pasteur de Dakar, Dakar, Sénégal.

18

19 Soa Fy Andriamandimby (soafy@pasteur.mg)

20 Cyril Viarouge (cyril.viarouge@anses.fr)

21 Jean-Marc Reynes (jean-marc.reynes@inserm.fr)

22 Jean-Pierre Ravalohery (jpierre@pasteur.mg)

23 Corinne Sailleau (corinne.sailleau@anses.fr)

24 Amadou Alpha Sall (asall@pasteur.sn)

25 Michael Luciano Tantely (lucinambi@pasteur.mg) 
26 Nohal Elissa (nohal_elissa@yahoo.com)

27 Eric Cardinale (eric.cardinale@cirad.fr)

28 Stephan Zientara (szientara@vet-alfort.fr)

29 Jean-Michel Heraud (jmheraud@pasteur.mg)

30

31 Corresponding author: Jean-Michel Heraud, Virology Unit, Institut Pasteur de Madagascar,

32 Antananarivo 101, Madagascar. Tel: +261202241272. Email: jmheraud@pasteur.mg

33

34 Highlights

35

- Bluetongue virus serotype $2(\mathrm{BTV}-2)$ circulates in Madagascar.

36

- BTV is endemic and highly prevalent among cattle

37

- Yearly incidence among cattle suggests low pathogenicity of circulating strains

38

39 


\section{Abstract}

41 So far, no published data was available concerning the circulation of Bluetongue virus (BTV) in Madagascar. During a survey on Rift Valley Fever, we were able to detect a virus

43 belonging to BTV. Therefore, we conducted a study aiming at characterizing molecularly the

44 BTV isolated and assess the importance of circulation of BTV in Madagascar. A total of 454,393 sera from ruminants selected randomly by stratification and sampled in 30 districts of 46 Madagascar were tested for BTV. Moreover, 175 cattle were followed during 11 months. 47 Phylogenetic analyses were performed from virus isolated from unfed pools of mosquitos.

48 Overall, the estimated mean seroprevalence of infection at the national level was $95.9 \%(95 \%$ 49 CI: [95.2-96.5]) in cattle and 83.7\% (95\% CI: [81.4-85.9]) in small ruminants. Estimation of 50 incidence rate was 54 per 100 cattle-years assuming that the incidence rate is constant all year 51 along. Phylogenetic analyses revealed that BTV detected belong to serotype 2.

52 In conclusion, our results showed that BTV is endemic in Madagascar and highly prevalent 53 among cattle. In our study we did not work on the vector involved in transmission of BTV in 54 cattle. Thus, research should be conducted to better describe epidemiology of BTV in 55 Madagascar including vectors and assess economic impact of the disease associated to BTV 56 infections.

57

\section{Keywords}

59 Bluetongue virus, Bovidae, Madagascar.

60 


\section{Background}

62 Bluetongue disease is a disease of ruminants caused by Bluetongue Virus (BTV). This 63 arthropod-borne virus is transmitted primarily by biting midges belonging to the Culicoides

64 genus (reviewed in Coettze 2012) (Coetzee et al., 2012a; Coetzee et al., 2012b). BTV is 65 circulating widely and its distribution pattern is related to the distribution of its vectors. BTV 66 is believed to have expanded in recent years as a possible result of climate warming (Purse et 67 al., 2005; Tabachnick, 2004). Areas like Northern and Western Europe, previously BTV-free were recently affected by the disease (Wilson and Mellor, 2009). Direct or indirect economic impacts were important in some areas of the world (Dungu et al., 2004a; Maclachlan, 2010; MacLachlan and Osburn, 2006; Tabachnick et al., 1996). BTV can cause severe disease in certain species of sheep, especially European fine wool and mutton breeds; however in endemic regions, local ruminants do not express clinical disease (Coetzee et al., 2012b). The clinical signs of BTV infection can vary between species. Sheep may have mainly fever, serous bloody nasal discharge, edema erosions and ulcers. Cattle and other ruminants may have ocular discharge, conjunctivitis, oral mucosal congestion, ulceration of muzzle, and teats (reviewed in Maclachlan, 2009) (Maclachlan et al., 2009). Previous studies showed that ruminants of African origin are apparently resistant to the infection (Fernandez-Pacheco et al., 2008; Mauroy et al., 2008). This resistance to BTV might explain why the disease was never described in Madagascar. In this study, we describe for the first time the detection of BTV serotype 2. Moreover, serosurvey amongst cattle revealed high seroprevalence of BTV

81 infection and large distribution of the virus in Madagascar.

\section{Methods}

\section{Specimen collection}

84 A total of 12,785 adults mosquitoes were collected on April 2009 in Fianarantsoa and 85 Ambalavao (Central South of Madagascar) during investigations due to Rift Valley Fever 
outbreaks. Mosquitoes were pooled (23-30) by species and then stored at $-80^{\circ} \mathrm{C}$. A total of

87390 pools containing monospecies of unfed female mosquitoes were grinded and supernatants were collected for subsequent viral analysis.

To address seroprevalence of BTV infection, we used sera from cattle and small ruminants collected in Madagascar in August 2008 during Rift valley fever outbreak. Sampling methods were described in Jeanmaire et al., 2011 (Jeanmaire et al., 2011). Briefly, Madagascar was divided into 10 sampling areas representing the combination of two stratification factors, the cattle density and the different ecozones. In these 10 sampling areas, 30 districts were randomly sampled. In each district 33 to 200 animals were sampled. Only animals that were born and lived in the same sampling area were considered.

For estimation of incidence, we included retrospectively sera collected from a cohort of cattle

97 from 5 and 3 villages located respectively in the Southwestern (Tulear II district) and Northwestern (Mampikony district) regions of Madagascar (Figure 1A). These two districts were chosen because of their agro-system differences. Tulear II is a semi-arid ecosystem and Mampikony has an environment of a dry and deciduous forest. In these study sites, 20 to 30 cattle were sampled and followed up monthly from May 2010 to April 2011. In collaboration

102 with veterinary service and the farmers, cattle included in this cohort study were firstly 103 identified and marked using number hooked around their neck. Sera from these cattle were collected monthly by a study veterinarian and were stored in $-80^{\circ} \mathrm{C}$ until use.

\section{Viral isolation and detection}

106 Virus isolation was performed on mosquito AP61 cell lines and virus identification was firstly 107 performed by an indirect immunofluorescence assay (IFI) as previously described (Digoutte et 108 al., 1992; Ratovonjato et al., 2011). One pool containing supernatant of Anopheles squamosus 109 individuals tested positive for BTV and was subsequently analyzed (see viral detection and 110 analysis). (Ratovonjato et al., 2011). 
111 Nucleic acid sample preparation, RT-PCR reactions and sequencing

112 Total RNA was extracted from $100 \mu \mathrm{L}$ of infected culture cells using the QIAcube robot 113 (Qiagen, Courtaboeuf, France) and the QIAamp Viral kit (Qiagen, Courtaboeuf, France)

114 according to the manufacturer's instructions. Finally, the RNAs were eluted with $50 \mu \mathrm{L}$ of 115 ultrapure water. Reverse transcription (RT) and amplification (PCR) were performed using a 116 commercial real-time RT-PCR kit (ADI-352, AES) according to the manufacturer's 117 instructions. For the segment 2 sequencing, RT-PCR were performed using a single tube RT118 PCR method and following the "One-step RT-PCR Kit" protocol (Qiagen, Courtaboeuf, 119 France). Group-specific primer-pairs derived from the nucleotide sequence data of genome 120 segment 2 of BTV available in GenBank were used (not described). Amplified RT-PCR 121 products were sequenced directly, in both directions, using the primer-pairs (Eurofins MWG 122 Operon, Ebersberg, Germany). Sequences were assembled by SeqMan (DNAstar programs, 123 Lasergene) and compared to the homologous sequences available in GenBank. Sequence 124 alignments were performed using MegAlign-Clustal V method (DNAstar software).

\section{Serological Analysis}

126 Serological tests were performed using LSIVet ${ }^{\mathrm{TM}}$ Ruminant Bluetongue Advanced II - Serum 127 ELISA Kit (LSI, Lissieu, France). This kit which is based on the principle of a blocking 128 ELISA, has been shown to detect specific antibodies directed against VP7 of all BTV 129 serotypes without cross reactions against antibodies induced by Epizootic Hemorrhagic 130 Disease Virus and has a high level of sensitivity and specificity (Niedbalski, 2011).

\section{Data analysis}

132 Statistical analysis was performed using R software version 3.1.2 (R Core Team (2014)). Data 133 were described nationwide and on stratification by sampling zone. Mean seroprevalence of 134 antibodies directed against BTV was estimated at the national level and by sampling zone 135 with accompanying 95\% confidence interval (CI). Student's t-test was used to compare mean 
age of two sub population, Chi-square test was used to compare frequency between two or

137 more sub population with $\mathrm{p}=0.05$ as degree of signification. Odds ratio (OR) were calculates to quantify effects of age in seroprevalence. Survival analysis was used to assess incidence rate, and median time from birth to seroconversion for the cohort population of cattle. Event is defined as ELISA positive during cohort observation. Time to seroconversion is defined as

141 time from birth to seroconversion. In this study the time point is defined as the end of the

142 survey. Animal is right censored if at the time point it did not have IgG against BTV or if 143 survey of cattle did not reach the time point. Animals were left-censored when time to 144 seroconversion could not be estimated because they were seropositive for BTV (IgG) at the 145 beginning of the survey.

146 Results

\section{Virus detection and molecular analysis}

148 Molecular analysis of virus isolated the supernatant of Anopheles squamosus individuals from 149 Ambalavao inoculated in mosquito cells (AP61) revealed that genomic segment 2 (encoding 150 the VP2 serotype-specific protein) of the isolate belonged to the serotype BTV-2 (Figure 2). 151 The comparison with homologous sequences available in GenBank showed a nucleotide 152 identity from 79.5 to $99 \%$ (data not shown).

\section{Serological results}

154 To assess the seroprevalence of BTV, a total of 4,393 samples (3,395 cattle and 998 small 155 ruminants: sheep and goats) from 30 of the 114 districts of Madagascar were tested.

156 The cattle population had a range of age from 4 months to 19 years, with a median age at 5 157 years and a mean at 5.5 (123 missing data). Small ruminant had a range of age population 158 from 6 months to 7 years, with a median age at 2 years and a mean at 2.4 (244 missing data). 159 The sex ratio (M/F) was 1.37 (26 missing data) and 0.4 (4 missing data) in cattle and small ruminants respectively. Fifteen percent of cattle were sampled in slaughterhouses, $46.5 \%$ on 
161 farms, and $6.2 \%$ in markets. Most of the small ruminants $(97.7 \%)$ were sampled in farms.

162 Overall, 95.9\% (95\% IC $=[95.2-96.5])$ of cattle sampled and $83.8 \%(95 \%$ IC $=[81.4-85.9])$

163 of small ruminants sampled showed detectable antibodies levels against BTV indicating past

164 infections. Twenty-one $(0.62 \%)$ cattle and $19(1.9 \%)$ little ruminants presented doubtful

165 results. Due to small amount of sera available, we were not able to re-test samples with

166 doubtful results. In all sampling areas there were animals with antibodies against BTV with a

167 seroprevalence in animals ranging from $85.2 \%$ (one district of zone 10) to $100 \%$ (Figure 1B).

168 The seroprevalence of infection was significantly higher in males compared to females in

169 cattle (Pearson's Chi-squared test $p=0.001$ ) but not in small ruminants (Pearson's Chi-squared 170 test $p=0.075$ ). Prevalence of antibodies against BTV increased significantly with the age in 171 cattle with an $\mathrm{OR}=1.24$ (CI 95\% [1.15-1.35], Pearson's Chi-squared test $p<0.0001)$ but not in 172 small ruminants (Pearson's Chi-squared test $p=0.69$ ). The value of OR showed more 173 important risk depending on age category (Table 1). There were no significant differences in 174 mean BTV-seroprevalence between animals sampled in farm, slaughterhouse or market.

175 To assess incidence-rate of BTV infection, a cohort of 182 cattle sampled from 2 regions of 176 Madagascar was included. Age was missing for 7 animals that were then excluded from our 177 statistical analysis. This cohort had a range of age from 7 to 12 months, with a median age at 1788.7 months. Sex-ratio was 0.9 (2 missing data). From this cohort of 175 cattle, $77.7 \%(n=136)$ 179 had already IgG against BTV; 39 cattle remained seronegative at the beginning of the survey. 180 Mean age of IgG positive population was significantly higher to mean age of remaining at risk 181 population (Student's t-Test $p=0.03$ ). Difference of seroprevalence was significantly more 182 important in Northwestern region than Southern region (Pearson's Chi-squared test $p<10^{-3}$ ). 183 No significant differences were observed between sexes concerning seropositivity of BTV in 184 this cohort. During this longitudinal survey, 1 animal was lost before its seroconversion; and 18519 seroconversions were observed. The median time to seroconverion was 9 months $(95 \% \mathrm{CI}$ : 
[8-9.5]) (Figure 3). Estimation of incidence rate was 89.5 per 100 cattle-year assuming this

187 incidence rate is constant.

\section{Discussion}

189 Our study confirms the circulation of BTV serotype 2 and the widespread distribution of this 190 virus amongst domestic ruminant from Madagascar. The molecular analysis of genome 191 segment 2 of the strain isolated in this study showed a high homology in nucleotides (99\%) 192 with the homologous gene from a strain isolated in 2009 in Reunion Island, $800 \mathrm{~km}$ to the 193 East from Madagascar (Sailleau et al., 2012). These data suggest that the same strain has been 194 circulating on both islands.

195 No clinical manifestations due to BTV infection were reported in Madagascar during the last 196 decade except a suspicion of a BTV outbreak among cattle in the southern region of 197 Madagascar in 1999-2000. Unfortunately, this outbreak was not confirmed by laboratory 198 testing (Herbas J, personal communication). The high seroprevalence of BTV infection and 199 the estimated incidence are in favor of a silent circulating of BTV in cattle of Madagascar as 200 observed in other parts of Africa and in all of BTV enzootic-areas (Gibbs and Greiner, 1994; 201 MacLachlan and Osburn, 2006). The lack of clinical manifestation may be due to this high 202 seroprevalence. Indeed, Park et al., have demonstrated that areas with intermediate 203 seroprevalence have high number of cases reporting whereas low case reporting was 204 associated with a high seroprevalence (Park et al., 2013). Only one unpublished study has 205 evaluated seroprevalence of BTV infection in small ruminants of Madagascar (Rasamoelina206 Andriamanivo, Dakar: UCAR, 2005). Indeed, this study showed a seroprevalence of 17.7\% 207 (n=92) amongst 520 sheep sampled in the district of Ambatondrazaka in 2005 (East part of 208 Madagascar). In the same district, three years later, we found a seroprevalence of antibodies 209 against BTV of 100\% (95\% CI, [89.6-100]) amongst cattle using the same assay. Although 210 we cannot exclude a difference in terms of risk of infection between cattle and sheep, the 
211 actual seroprevalence observed amongst both species and the clinically described BTV

212 epidemic in 1999-2000, could be in favor of a hypothesis of a fairly recent introduction in

213 Madagascar. Nevertheless, due to lack of historical data at the national level, we could not

214 confirm our hypothesis.

215 Our results indicate that BTV infection increased significantly with age of ruminants 216 demonstrating an enzootic circulation. We also demonstrate that annual incidence of the

217 disease was 54 per 100 cattle-year. This incidence could be in favor of many episodes of 218 circulation per year or a yearly circulation of BTV. Nevertheless, since BTV infection seems 219 to be silent we could only address the question of seasonality and/or episodes of circulation 220 with yearly virological surveillance.

221 Our study has some limitation. Indeed, BTV was detected from a pool of mosquitoes which is 222 uncommon. No BTV wild strain was present in the laboratory at the time of viral isolation and 223 detection of the Malagasy strain. Thus, a laboratory contamination at this level can be 224 excluded. Some fresh blood from cattle was perhaps still present in the female mosquitoes 225 constitutive of the BTV positive pool. Biting midges may have also contaminated mosquito's 226 pools. Unfortunately, due to lack of specimen we could not look for DNA material from cattle 227 or midges in the positive pool. Finally, incidence was estimated considering that rate of 228 infection was constant all year around which might not be the case. A longer survey period 229 that includes entomological and virological surveillance will be needed to address the 230 question of seasonality or period of BTV transmission.

\section{Conclusions}

232 Our study reports the first BTV isolation in Madagascar. Madagascar is a BTV endemic-area 233 and we can conclude that at least serotype 2 of BTV have circulated in Madagascar. Farming 234 ruminants are largely traditional with local breeds. However importation of ameliorated 235 breeds in dairy farms raises concern about the susceptibility of these animals to BTV 
circulating in Madagascar. More studies about the incidence, the circulating serotypes, the

237 vectors and clinical manifestations of BTV in Madagascar should be conducted at a larger 238 scale to evaluate the associated risk for cattle. Due to high circulation of BTV in Madagascar, 239 vaccine implementation can prevent infection amongst introduced breeding ruminants to 240 avoid economic loss. Nevertheless, this implementation should be discussed due to the risk of 241 recombination between vaccine and circulating strains (Dungu et al., 2004b).

\section{Acknowledgements}

244 We would like to thank Dr Harena Rasamoelina-Andriamanivo for providing data on cattle.

\section{Funding}

246 This study was funded by an internal grant from IP Madagascar. Sera from cohort of cattle

247 were obtained from study conducted in the frame of AnimalRisk-OI, a research program on 248 emerging animal diseases in the Indian Ocean, funded by FEDER POCT (European Union, 249 Regional Council of Reunion and French government). Sera from transversal study were 250 obtained during survey of Rift valley fever funded by Word Health Organization and Food 251 and Agriculture Organization through the Central Emergency Response Fund of the United 252 Nations.

\section{Competing interests}

254 The authors declare no conflict of interest. None of the authors have financial or personal 255 conflicts of interest related to this study. The corresponding author has full access to all data 256 in the study and final responsibility for the decision to submit this publication.

\section{Authors' contributions}

258 JMH and SFA executed and coordinated the study, analyzed data and coordinated all process 259 of writing of this work. CV, JMR, JPR and CS performed viral diagnosis and analysis. AAS provided reagents and help writing the paper. MLT and NE conducted vector survey and help 
design the study. EC helped with serological analysis. SZ helped design the study and

262 participated to the writing.

\section{References}

Coetzee, P., Stokstad, M., Venter, E.H., Myrmel, M., Van Vuuren, M., 2012a. South Africa. Virol J 9, 198.

Coetzee, P., Van Vuuren, M., Stokstad, M., Myrmel, M., Venter, E.H., 2012b. Bluetongue virus genetic and phenotypic diversity: towards identifying the molecular determinants that influence virulence and transmission potential. Vet Microbiol 161, 1-12.

Digoutte, J.P., Calvo-Wilson, M.A., Mondo, M., Traore-Lamizana, M., Adam, F., 1992. Continuous cell lines and immune ascitic fluid pools in arbovirus detection. Research in virology 143, 417-422.

Dungu, B., Gerdes, T., Smit, T., 2004a. The use of vaccination in the control of bluetongue in southern Africa. Vet Ital 40, 616-622.

Dungu, B., Potgieter, C., Von Teichman, B., Smit, T., 2004b. Vaccination in the control of bluetongue in endemic regions: the South African experience. Dev Biol (Basel) 119, 463-472.

Fernandez-Pacheco, P., Fernandez-Pinero, J., Aguero, M., Jimenez-Clavero, M.A., 2008. Bluetongue virus serotype 1 in wild mouflons in Spain. Vet Rec 162, 659-660.

Gibbs, E.P., Greiner, E.C., 1994. The epidemiology of bluetongue. Comp Immunol Microbiol Infect Dis 17, 207-220.

Jeanmaire, E.M., Rabenarivahiny, R., Biarmann, M., Rabibisoa, L., Ravaomanana, F., Randriamparany, T., Andriamandimby, S.F., Diaw, C.S., Fenozara, P., de La Rocque, S., Reynes, J.M., 2011. Prevalence of Rift Valley fever infection in ruminants in Madagascar after the 2008 outbreak. Vector Borne Zoonotic Dis 11, 395-402.

Maclachlan, N.J., 2010. Global implications of the recent emergence of bluetongue virus in Europe. Vet Clin North Am Food Anim Pract 26, 163-171, table of contents.

Maclachlan, N.J., Drew, C.P., Darpel, K.E., Worwa, G., 2009. The pathology and pathogenesis of bluetongue. J Comp Pathol 141, 1-16.

MacLachlan, N.J., Osburn, B.I., 2006. Impact of bluetongue virus infection on the international movement and trade of ruminants. J Am Vet Med Assoc 228, 1346-1349.

Mauroy, A., Guyot, H., De Clercq, K., Cassart, D., Thiry, E., Saegerman, C., 2008. Bluetongue in captive yaks. Emerg Infect Dis 14, 675-676.

Niedbalski, W., 2011. Evaluation of commercial ELISA kits for the detection of antibodies against bluetongue virus. Pol J Vet Sci 14, 615-619.

Park, A.W., Magori, K., White, B.A., Stallknecht, D.E., 2013. When more transmission equals less disease: reconciling the disconnect between disease hotspots and parasite transmission. PLoS One 8, e61501. 
Purse, B.V., Mellor, P.S., Rogers, D.J., Samuel, A.R., Mertens, P.P., Baylis, M., 2005. Climate change and the recent emergence of bluetongue in Europe. Nat Rev Microbiol 3, 171-181.

Ratovonjato, J., Olive, M.M., Tantely, L.M., Andrianaivolambo, L., Tata, E., Razainirina, J., Jeanmaire, E., Reynes, J.M., Elissa, N., 2011. Detection, isolation, and genetic characterization of Rift Valley fever virus from Anopheles (Anopheles) coustani, Anopheles (Anopheles) squamosus, and Culex (Culex) antennatus of the Haute Matsiatra region, Madagascar. Vector Borne Zoonotic Dis $11,753-759$.

Sailleau, C., Zanella, G., Breard, E., Viarouge, C., Desprat, A., Vitour, D., Adam, M., Lasne, L., Martrenchar, A., Bakkali-Kassimi, L., Costes, L., Zientara, S., 2012. Co-circulation of bluetongue and epizootic haemorrhagic disease viruses in cattle in Reunion Island. Veterinary microbiology 155, 191-197.

Tabachnick, W.J., 2004. Culicoides and the global epidemiology of bluetongue virus infection. Vet Ital 40, 144-150.

Tabachnick, W.J., MacLachlan, N.J., Thompson, L.H., Hunt, G.J., Patton, J.F., 1996. Susceptibility of Culicoides variipennis sonorensis to infection by polymerase chain reaction-detectable bluetongue virus in cattle blood. Am J Trop Med Hyg 54, 481-485.

Wilson, A.J., Mellor, P.S., 2009. Bluetongue in Europe: past, present and future. Philos Trans R Soc Lond B Biol Sci 364, 2669-2681. 
328 Table 1. Relation between age group and seroprevalence of Bluetongue virus infection in 329 cattle population, Madagascar, 2008 survey.

330

331 Figure 1. Seroprevalence of Bluetongue virus infection, Madagascar 2008-2009. A. Sampled 332 area. Longitudinal study area: Tulear II in the Southern region ( 3 sites) and Mampikony in the 333 Northern Region (2 sites). Sample district area: 30 districts sampled for the survey. B.

334 Seroprevalence of BTV in sampled area. White areas represent districts where no sample was 335 collected.

336

337 Figure 2. Phylogenetic tree based on the full-length segment 2 sequences from BTV-2 strains 338 selected in GenBank (clustal analysis)

339

340 Figure 3. Estimation of survival parameters during longitudinal survey, Madagascar 2010341 2011. Kaplan-Meier curve. 
Table 1. Relation between age group and prevalence of Bluetongue virus infection in cattle population, Madagascar, 2008 survey.

\begin{tabular}{lccc}
\hline Age group (years) & OR & p-value* & $95 \% \mathrm{CI}^{* *}$ \\
$\leq 5 * * *$ & 1 & & \\
$15-10]$ & 2.5 & 0.000 & {$[1.6-3.9]$} \\
] $10-20]$ & 9.5 & 0.025 & {$[1.3-68.4]$} \\
\hline
\end{tabular}

\footnotetext{
*p-value: Fisher's exact test (univariate analysis), OR: univariate analysis $* * 95 \%$ CI: Confidence interval of OR

${ }^{* * *} \leq 5$ : reference category
} 


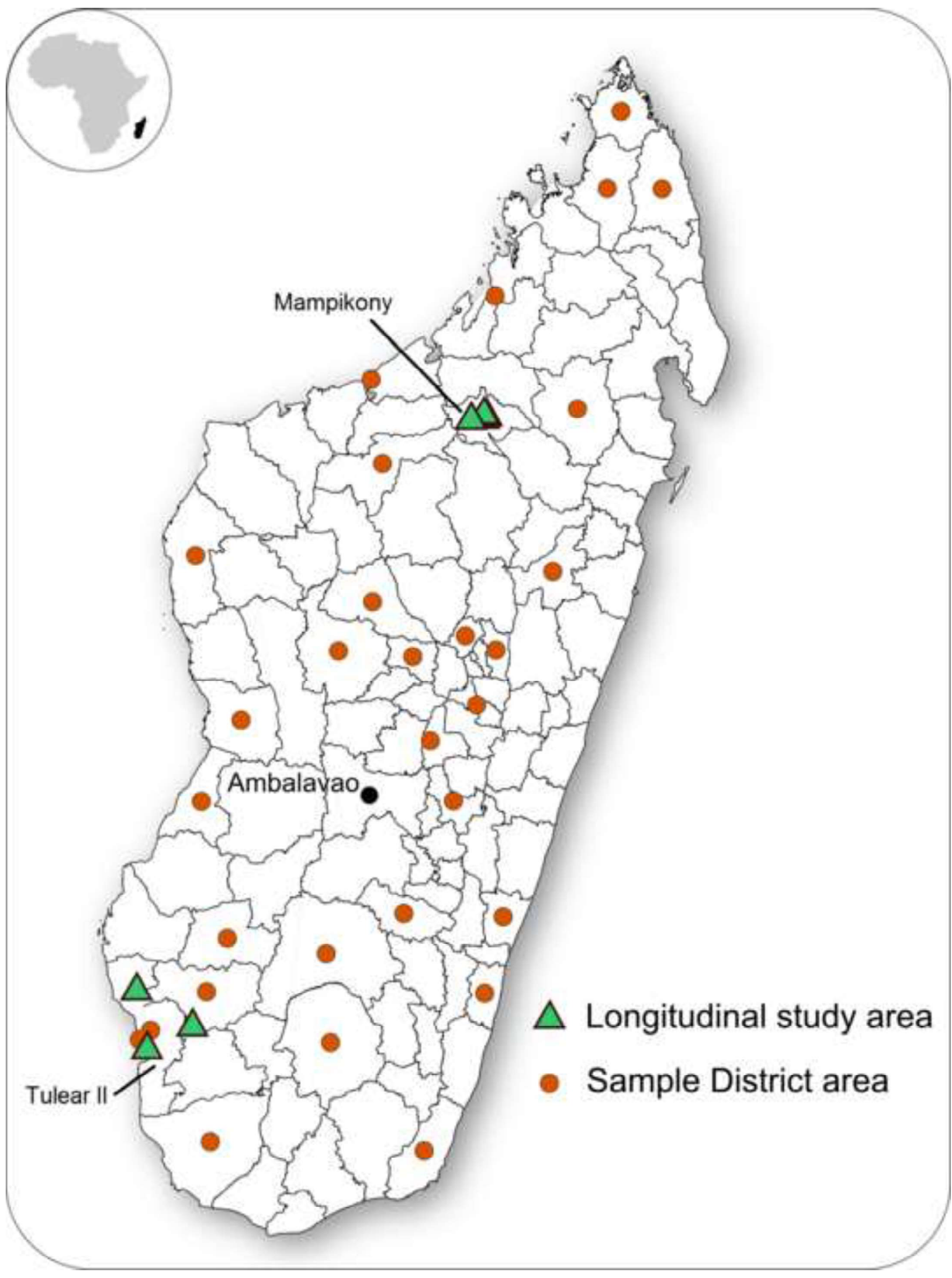




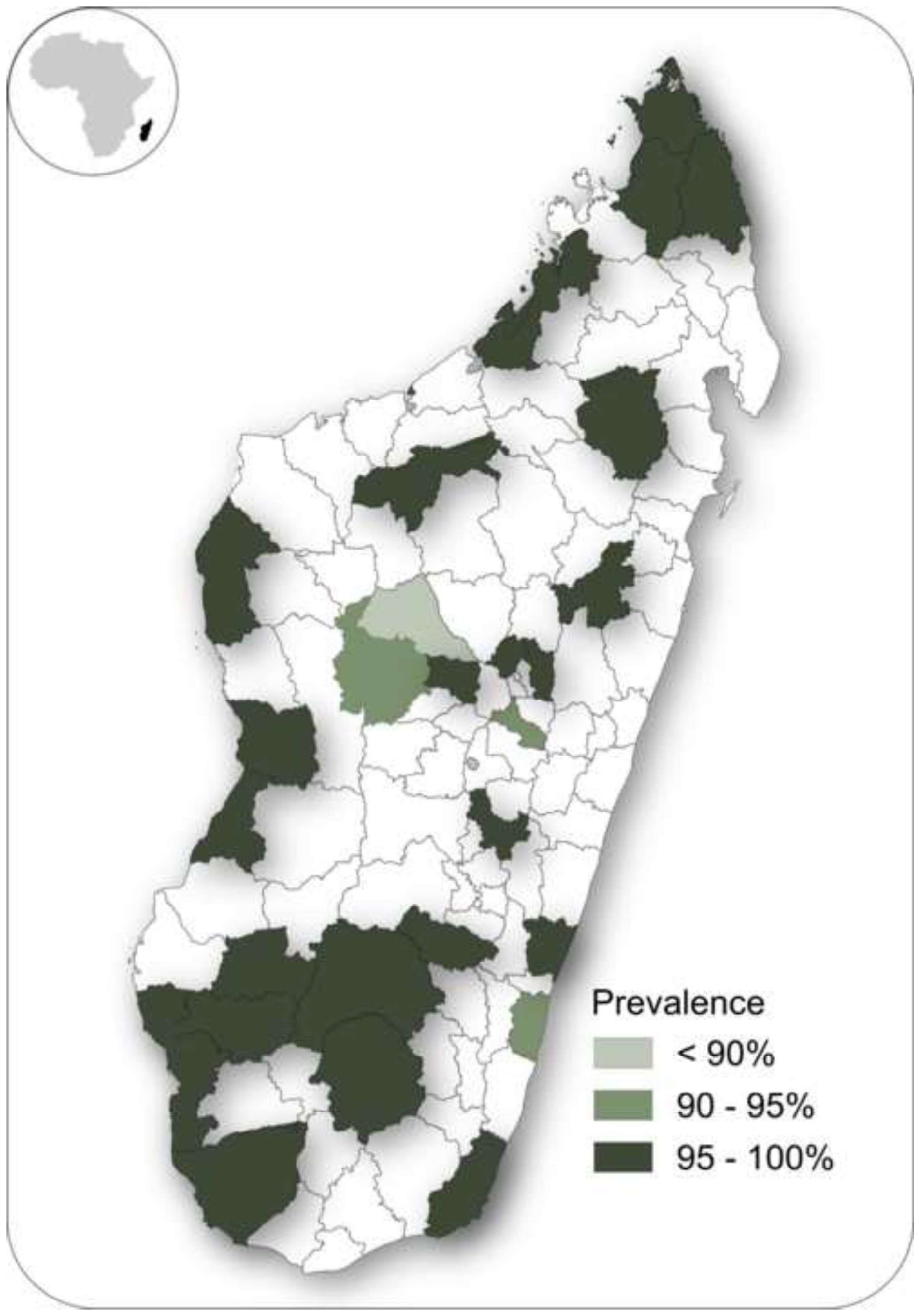




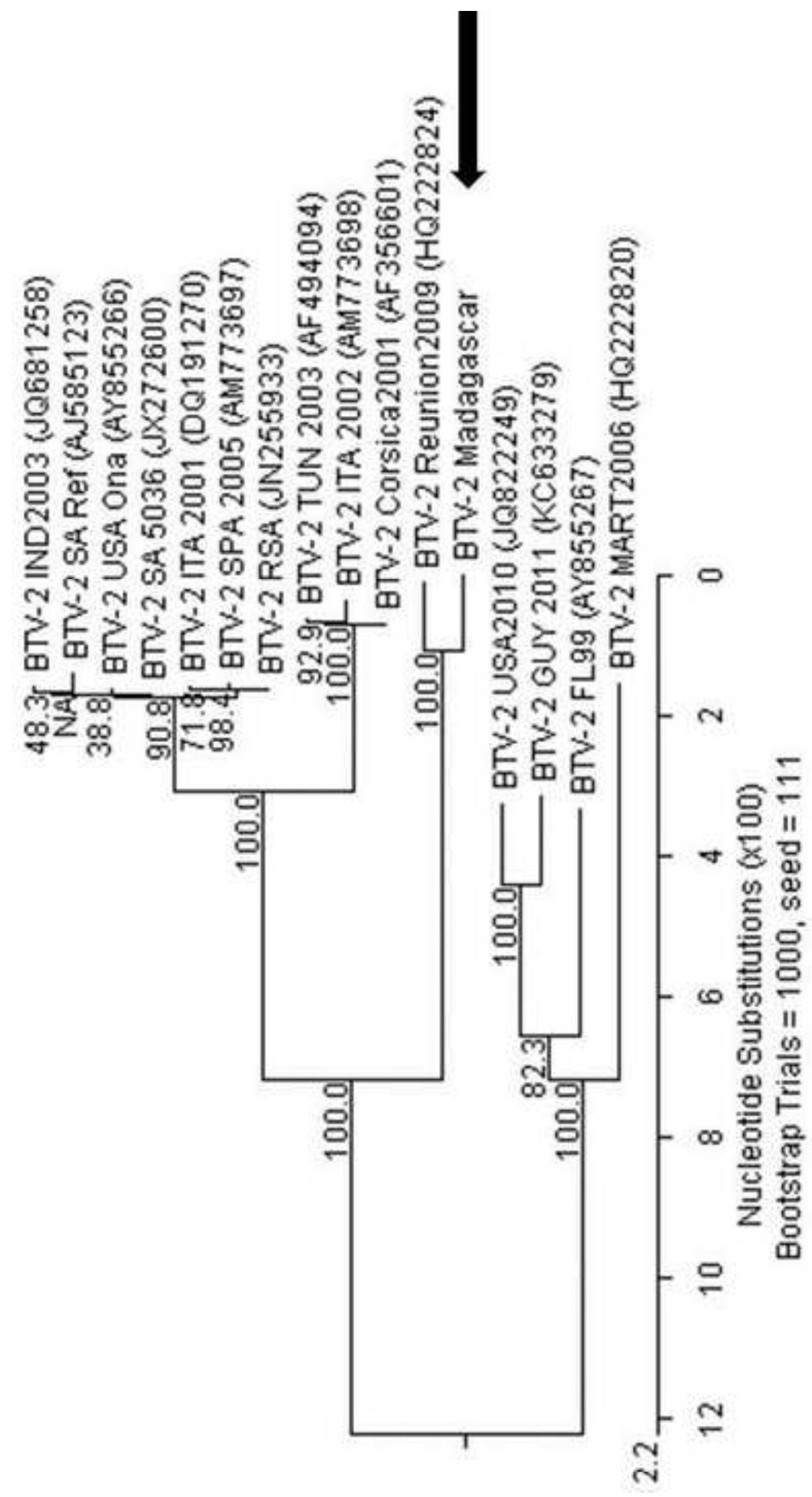




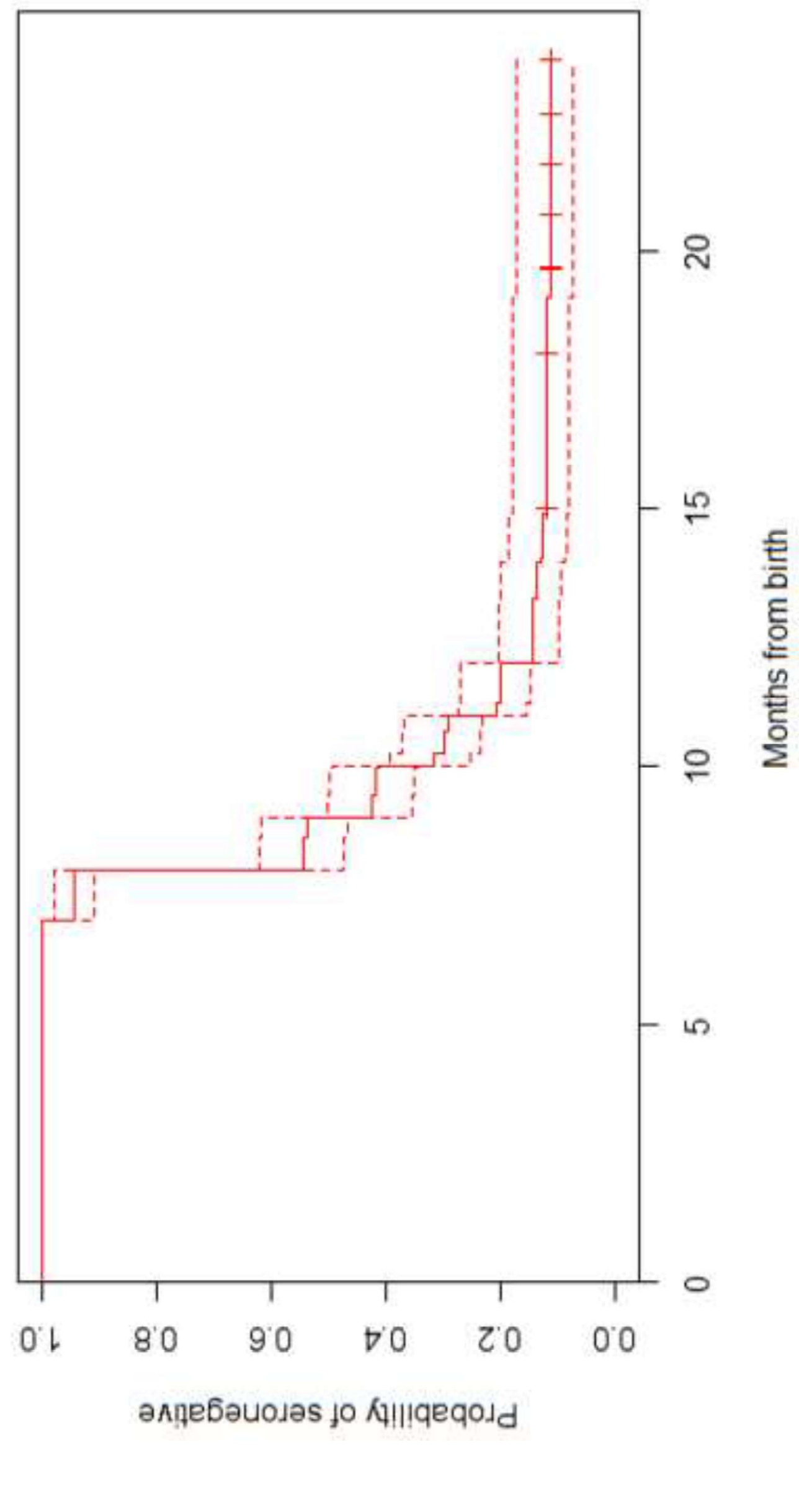

